\title{
A Review of Prevention, Diagnosis, and Treatment of Relative Energy Deficiency in Sport in Artistic (Synchronized) Swimming
}

\author{
Sherry Robertson \\ Alberta Health Services \\ Margo Mountjoy \\ McMaster University and FINA Sports Medicine Committee
}

\begin{abstract}
The syndrome of relative energy deficiency in sport (RED-S) is a clinical entity characterized by low energy availability, which can negatively affect the health and performance of both male and female athletes. The underlying mechanism of RED-S is an inadequacy of dietary energy to support optimal health and performance. This syndrome refers to impaired physiological function, including metabolic rate, menstrual function, bone health, immunity, protein synthesis, and cardiovascular health, with psychological consequences that can either precede (through restrictive dietary habits) or result from RED-S. The term RED-S extends beyond the condition termed the "Female Athlete Triad." Formerly known as synchronized swimming, artistic swimming is an Olympic sport requiring a high level of fitness as well as technical skill and artistry. The risk of RED-S is high in artistic swimming as it is an aesthetic, judged sport with an emphasis on a lean physique. RED-S is of significant concern in the sport of artistic swimming because of the potential negative effects on physical and mental health as well as consequences on athletic performance. This paper reviews health and performance consequences associated with low energy availability resulting in RED-S in artistic swimming. Medical and nutritional considerations specific to artistic swimming are reviewed, and methods to help detect and manage RED-S are discussed. Prevention and management of RED-S in this athlete population should be a priority for coaches, and the sport medicine professionals working with artistic swimming athletes should utilize the RED-S CAT, a Clinical Assessment Tool for screening and managing RED-S.
\end{abstract}

Keywords: energy availability, REDS, synchronized swimming

Relative energy deficiency in sport (RED-S) is a syndrome resulting from an energy deficiency relative to the balance between dietary energy intake (EI) and the energy expenditure (EE) required to support homeostasis, health, activities of daily living, growth, and sport. RED-S affects physiological function, including metabolic rate, menstrual function, bone health, immunity, protein synthesis, cardiovascular function, and psychological health (Mountjoy et al., 2014). The "Female Athlete Triad" is defined as a medical condition observed in athletic girls and women, comprising three components-that is, low energy availability (LEA), menstrual dysfunction (MD), and low bone mineral density (BMD) (Nattiv et al., 2007). The International Olympic Committee (IOC) Consensus Group coined the more comprehensive term, RED-S, to more accurately describe the pathophysiology and multisystem involvement that can affect both male and female athletes (Mountjoy et al., 2014). Recent evidence of an increased risk for LEA and the resulting health consequences of RED-S in male athletes includes weight-class combat sports, jockeys, rowers, cyclists, and runners (Barrack et al., 2017; Berkovich et al., 2016; Viner et al., 2015; Wilson et al., 2014). Although there are no published prevalence studies of RED-S specifically in artistic swimming, there is one study of female Scandinavian artistic

Robertson is with Alberta Health Services, Edmonton, AB, Canada. Mountjoy is with McMaster University, Hamilton, ON, Canada; and FINA Sports Medicine Committee, Lausanne, Switzerland. Address author correspondence to Sherry Robertson at Sherry.Robertson@albertahealthservices.ca. swimmers that indicated significant LEA with subsequent endocrine signs of energy conservation and fatigue following an intense training block (Schaal et al., 2017).

Artistic swimming requires a variety of athletic abilities, including endurance, power, agility, acrobatics, and flexibility. Athletes must precisely synchronize choreography with both their teammates and music (Robertson et al., 2014). Desired performance outcomes require that artistic swimmers train for long hours in a variety of exercise modalities (Mountjoy, 2009). The complex judging system evaluates components of technical skill, synchronization, and artistic impression. Body shape is not a judged component; however, there is considerable emphasis on body composition to achieve the desired aesthetic appearance. Due to the sport's aesthetic nature, which prioritizes leanness, the risk of RED-S is of concern for this athletic population, which now includes both males and females.

\section{The Sport of Artistic Swimming}

Artistic swimming is part of the summer Olympic program and is restricted to female athletes at the Olympic level. In addition, artistic swimmers compete at Continental and World Championships. The rules are governed by Fédération Internationale de Natation (FINA), the international governing body for aquatic sports. The "mixed" duet, introducing male athletes, is the newest event on the FINA calendar and was first presented at the 2015 World Championships. Given the recent addition of male athletes 
to the FINA sport program, and the small athlete pool $(n=11$ in 2017), there are no scientific data on RED-S in male artistic swimmers. However, as artistic sports are at high risk for RED-S, and RED-S can also occur in male athletes (Mountjoy et al., 2014), it can be postulated that male artistic swimmers may be at risk for the development of RED-S.

Table 1 summarizes the details of artistic swimming.

\section{Physiological Demands}

Artistic swimming demands a high level of overall fitness, incorporating many athletic abilities. A high sport-specific degree of complex technical skill is critical. Routines vary in length from 2 to 5 min, requiring aerobic endurance with many intermittent bursts of anaerobic power (Robertson et al., 2014). Complex, high-intensity movements requiring precise synchronization in a zero-gravity environment must be performed with perfection (Mountjoy, 2009). Chatard et al. (1999) found that the physiological profile (i.e., peak oxygen update, blood lactate concentration, and heart rate measured during a 400-m swim) of individual swimmers is positively linked to synchronized swimming skill. Other studies found that $45-50 \%$ of the time is spent underwater, thereby requiring exceptional breath control (Chatard et al., 1999; Homma, 1994). Modern routines incorporate more acrobatic maneuvers, which involve less total time underwater. However, long training sessions and technical movements performed within the high resistance of water require a broad range of cardiovascular and musculoskeletal strength.

\section{Energy}

\section{Energy Requirements}

There is a dearth of literature focused on estimating the energy requirements for elite artistic swimmers. Due to the nature of the sport, it is impossible to continuously measure $\mathrm{VO}_{2}$ during training, making it difficult to assess energy requirements and relative contributions of aerobic and anaerobic metabolism (Bante et al., 2007). A doubly labeled water method for measuring total EE of elite Japanese artistic swimmers during moderately intense training determined that the mean (SD) total EE was 11.5 (2.8) $\mathrm{MJ} /$ day (2,738 [672] kcal/day; Ebine et al., 2000). A study by Schaal et al. (2017) quantified EE, EI, and energy availability (EA) in artistic swimming, demonstrating how these variables changed during intense training prior to major international competitions.

\section{Table 1 Details of Artistic Swimming}

\begin{tabular}{|c|c|}
\hline Sport governing body & FINA \\
\hline $\begin{array}{l}\text { Size of sport governing body (number of national } \\
\text { federations) }\end{array}$ & 207 \\
\hline First year at Olympic games & 1984 \\
\hline Number of competitive events at World Championships & $9^{\mathrm{a}}$ \\
\hline Number of athletes at Olympic games & 72 \\
\hline Gender: F, MX & $\mathrm{F}+\mathrm{MX}$ \\
\hline Events at Olympic games: I/D/T & $\mathrm{I}+\mathrm{D}+\mathrm{T}$ \\
\hline
\end{tabular}

\section{Energy Availability}

The fundamental cause of RED-S is an inadequacy of dietary energy to support optimal health and performance (Mountjoy et al., 2014). With a reduction in EI and/or increased exercise volume, LEA will occur, causing disruptions of hormonal, metabolic, and functional characteristics (Loucks, 2004, 2011). EA is calculated as EI minus the energy cost of exercise relative to fat free mass (FFM). In healthy adults, a value of $45 \mathrm{kcal} / \mathrm{kg}$ FFM/day equals energy balance, and the health consequences of LEA occur at $<30 \mathrm{kcal} / \mathrm{kg} \mathrm{FFM} /$ day (Loucks, 2004). Schaal et al. (2017) demonstrated that the mean EA of these athletes at baseline was less than $30 \mathrm{kcal} / \mathrm{kg} \mathrm{FFM} /$ day, indicating that LEA may be a concern for many artistic swimmers.

\section{Health Consequences of RED-S}

RED-S has the potential to negatively affect all body systems, resulting in adverse health consequences. Prolonged LEA can contribute to nutrient deficiencies, chronic fatigue (CialdellaKam et al., 2014), and suppressed immune function resulting in an increased risk of illness (Venkatraman \& Pendergast, 2002), all of which can be detrimental to both health and athletic performances. Figure 1 depicts potential health consequences of RED-S.

Prevalence studies estimate up to $50 \%$ of exercising women have subtle menstrual abnormalities and 33\% suffer from amenorrhea (De Souza et al., 2010). The MD most commonly associated with RED-S is functional hypothalamic amenorrhea (FHA), which occurs when the hypothalamic-pituitary-gonadal hormone axis is

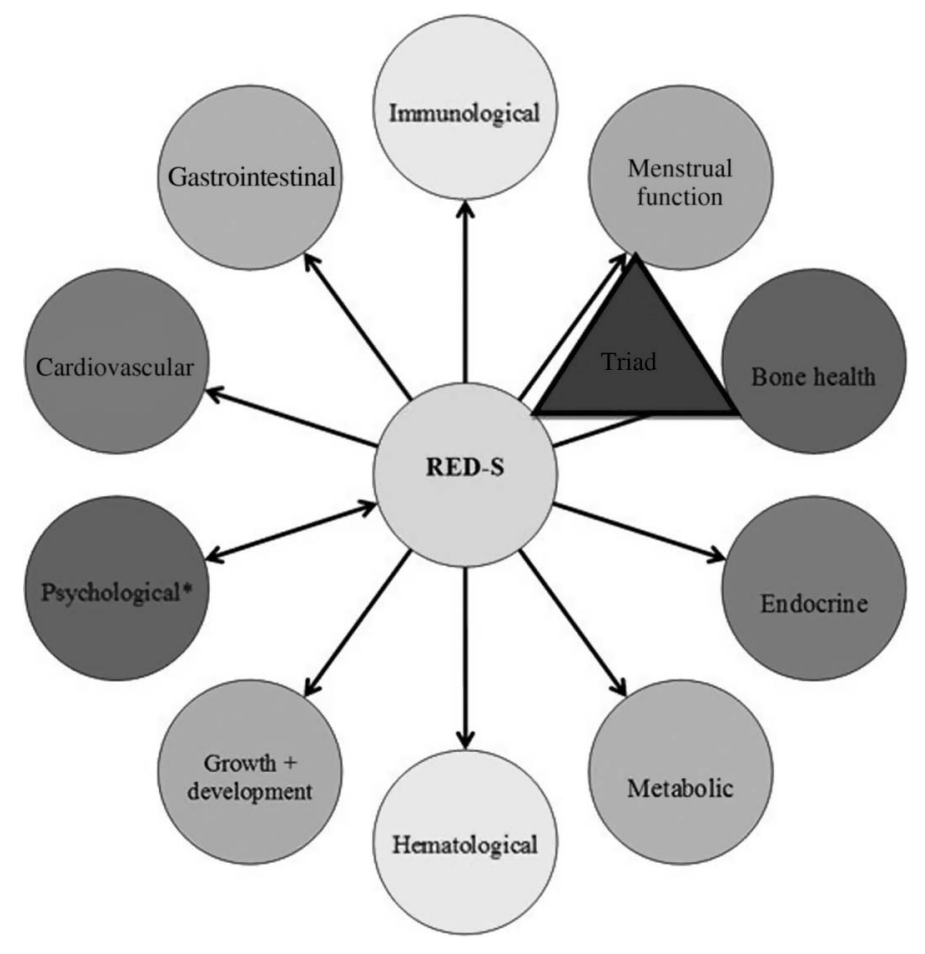

Figure 1 - Health consequences of relative energy deficiency in sport (RED-S). *Psychological consequences can either precede RED-S or be the result of REDS (Constantini, 2002). Adapted from "The IOC Consensus Statement. Beyond the Female Athlete Triad-Relative Energy Deficiency in Sport," by M. Mountjoy, J. Sundgot-Borgen, L. Burke, S. Carter, N. Constantini, C. Lebrun, ... A. Ljungqvist, 2014, British Journal of Sports Medicine, 48, pp. 491-497. Copyright 2014 by BMJ Publishing Group ltd. 
disrupted by LEA. Long-term physical consequences of FHA can include osteopenia/osteoporosis and potentially infertility (Sonntag \& Ludwug, 2012). A study by Sambanis et al. (2003) found that elite artistic swimmers had a delay in menarche of 0.6 years. Two studies (Ferrand et al., 2007; Ramsay \& Wolman, 2001) assessing the prevalence of MD in artistic swimmers have been published; however, the conclusions of these studies are challenged by the confounding factor of oral contraceptive (OC) use by the subjects.

RED-S can also contribute to the development of poor bone health mediated by the hormonal disruption and/or nutritional deficits (Ackerman et al., 2011, 2012). Maximum bone accrual occurs during adolescence, when training is heavy. Peak bone mass in women occurs around age 19, and around 20.5 years in males (Baxter-Jones et al., 2011). This is a critical time period, and disruption to bone formation due to LEA may be irreversible as evidence shows that the effect on bone formation is cumulative with multiple risk factors (Gibbs et al., 2014). The prevalence of osteopenia in athletes is estimated at between 22 and 50\% and osteoporosis at $13 \%$ (Khan et al., 2002). Liang et al. (2005) demonstrated lower BMD in the wrist of artistic swimmers $\left(0.414 \mathrm{~g} / \mathrm{cm}^{2}\right.$ in comparison with gymnasts $\left(0.540 \mathrm{~g} / \mathrm{cm}^{2}\right)$ and untrained controls $\left(0.474 \mathrm{~g} / \mathrm{cm}^{2}\right)$. Similar results were found in the wrist (Roby et al., 1988) and in the lower limb and lumbar spine (Tanaka et al., 2006) in artistic swimmers. However, these findings may be attributed to the fact that artistic swimming is not a weight-bearing sport.

\section{Performance Consequences of RED-S}

RED-S has the potential to affect the athlete's performance in sport (Mountjoy et al., 2014). Performance outcomes are more likely to be a motivating factor for athletes than negative health consequences, which may not prove sufficient incentive for athletes to change behavior due to a lack of an immediate consequence (Melin, Klungland Torstveit, et al., 2014). Functional impairments associated with LEA that negatively affect performance include increase in viral illnesses (Hagmar et al., 2008) and injuries (Rauh et al., 2010; Thein-Nissenbaum et al., 2011) and reduced responsiveness to training stimuli resulting in decreased performance (Vanheest et al., 2014). Figure 2 shows the potential negative effects on athletic performance.

\section{Disordered Eating and Eating Disorders}

Because they participate in a judged sport that emphasizes a lean appearance, artistic swimming athletes may be at higher risk for disordered eating (DE) and/or eating disorders (ED; Melin, Tornberg, et al., 2014; Rosendahl, 2009). Melin et al. (2015) found a high prevalence of ED, MD, and impaired bone health in elite endurance female athletes. Ferrand et al. (2007) found more than half of college-level artistic swimmers showed distorted body image with dissatisfaction, despite being in the healthy weight range. A Greek study showed that artistic swimmers had higher scores on The Eating Attitudes Test for EDs in comparison with swimmers and water polo players (Douka et al., 2008). Given that males now compete in this sport, they may also be at risk; however, there are no supporting data.

\section{Health Consequences}

For both males and females, negative health consequences of DE/EDs are numerous and can be fatal, as every body system

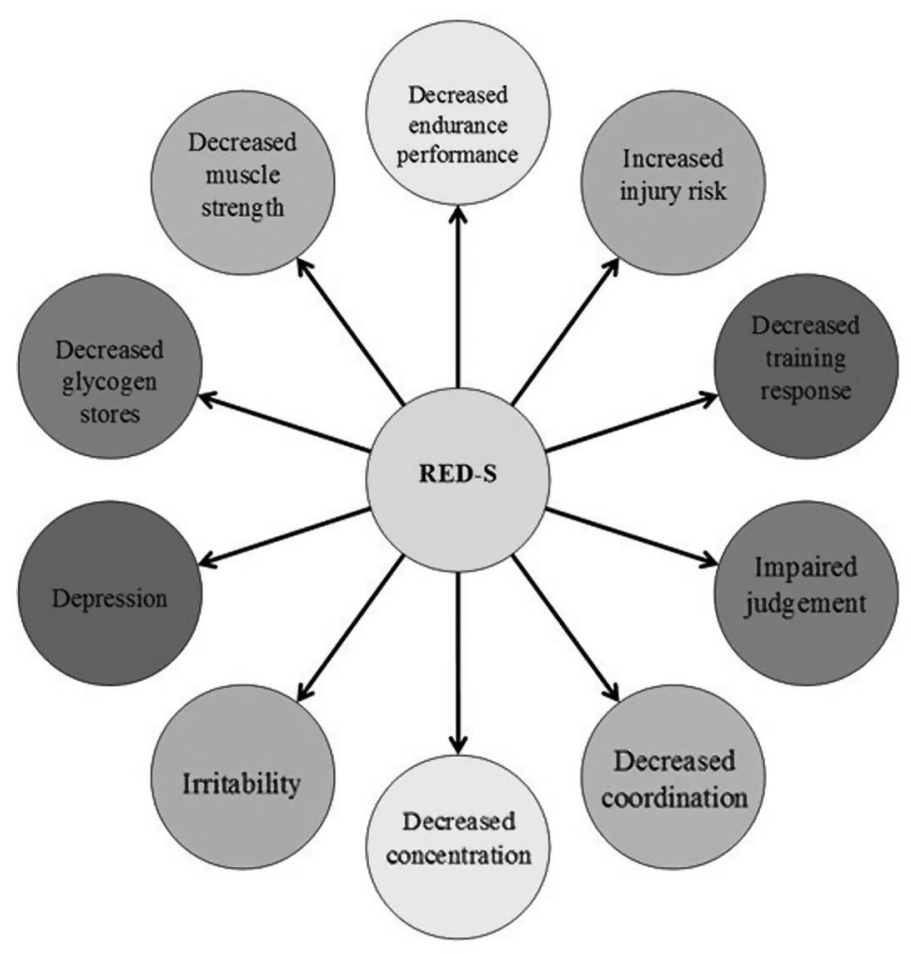

Figure 2 - Potential performance effects of relative energy deficiency in sport. *Aerobic and anaerobic performance (Constantini, 2002). Adapted from "The IOC Consensus Statement. Beyond the Female Athlete Triad-Relative Energy Deficiency in Sport," by M. Mountjoy, J. Sundgot-Borgen, L. Burke, S. Carter, N. Constantini, C. Lebrun, ... A. Ljungqvist, 2014, British Journal of Sports Medicine, 48, pp. 491-497. Copyright 2014 by BMJ Publishing Group ltd.

can be affected. Physical consequences of EDs can include delayed puberty, bone growth retardation, and decreased bone deposition. There are also psychological consequences, including depression, anxiety, and suicide (Melin, Tornberg, et al., 2014, 2015; Mountjoy et al., 2014).

\section{Prevention}

To prevent DE/EDs, the focus on "weight" as a performance marker should be minimized, and an environment ensuring that athletes are practicing eating behaviors that optimize performance should be encouraged (Melin, Tornberg, et al., 2014). National Sport Federations and Olympic Committees are encouraged to develop and implement healthy body composition policies for athletes to help protect them from the pressure to be thin.

\section{Assessment of RED-S}

RED-S is a medical diagnosis to be made following clinical and laboratory assessment by a trained health care professional (Mountjoy et al., 2015). Because symptoms of RED-S are subtle, screening and diagnosis can be challenging and require focused attention on the athlete at risk. To prevent long-term health consequences and improve sport performance, early detection is recommended (Mountjoy et al., 2014, 2015). The assessment for RED-S should be in the preseason Periodic Health Exam (Ljungqvist et al., 2009) to allow for early identification and treatment prior to the competition season. Screening should be mandatory given that artistic swimmers may not voluntarily report 
symptoms for fear of reprisal from the coach or with team selection. In contrast to nonathletes, a Norwegian study showed that athletes are reluctant to answer ED/DE questionnaires, but respond more truthfully to personal interviews, demonstrating the importance of "in person" screening for this component of RED-S (Martinsen \& Sundgot-Borgen, 2013). A Clinical Assessment Tool (RED-S CAT) was developed by the IOC to assist with the medical screening and management of the RED-S athlete. Based on the clinical assessment, the IOC RED-S CAT categorizes athletes into either the high risk (red light—no sport participation), moderate risk (yellow light—-modified and monitored sport participation), or low risk (green light-full sport participation). While the RED-S CAT requires scientific validation and further study, it can be a useful tool to guide decision making among medical and coaching staff (Mountjoy et al., 2015).

For artistic swimmers, the RED-S screening should include:

- Complete history for signs and symptoms relevant to RED-S, including:

- EA (Low Energy Availability in Females Questionnaire; Melin, Tornberg, et al., 2014)

$\circ$ ED and DE screens (Brief Eating Disorder Athlete Questionnaire; Martinsen 2014a, 2014b)

$\circ$ MD: delayed menarche (lack of menses $>15$ years), oligomenorrhea (menstrual cycles at intervals of $>35$ days), and amenorrhea (menstrual cycles at intervals $>90$ days; De Souza et al., 2014)

- Stress fractures or bone stress reaction

$\circ$ Frequent viral infections

- Targeted physical examination, which may consist of:

○ Body Mass Index $<17.5 \mathrm{~kg} / \mathrm{m}^{2}$ (De Souza et al., 2014)

○ Weight: <85\% expected; or $10 \%$ weight loss/month (De Souza et al., 2014)

- Tanner staging assessment

- Physical signs for other causes of MD (FHA is a diagnosis of exclusion)

- Bone health: if history of a bone stress injury

- Systolic blood pressure $<90 \mathrm{mmHg}$ and/or diastolic blood pressure $<60 \mathrm{mmHg}$ (Melin et al., 2015)

- Laboratory assessment of

- Fasting blood glucose $<4 \mathrm{mmol} / \mathrm{L}$

- Ferritin <25 $\mu \mathrm{g} / \mathrm{L}$ (Petkus et al., 2017).

- Vitamin D

- Endocrine function (luteinizing hormone, follicle-stimulating hormone, and estradiol) according to the phase of the cycle

$\circ$ Free triiodothyronine $<3.5 \mathrm{pmol} / \mathrm{L}$ (Melin et al., 2015)

$\circ$ Low-density lipoprotein cholesterol $>3.0 \mathrm{mmol} / \mathrm{L}$ (Melin et al., 2015)

- Fasting insulin $<20 \mathrm{pmol} / \mathrm{L}$ (Melin et al., 2015)

- Insulin-like growth factor-1 (Melin et al., 2015)

- Resting metabolic rate $\leq 29 \mathrm{kcal} / \mathrm{kg}$ FFM (Melin et al., 2015)

- BMD by dual-energy X-ray absorptiometry: $<-1.0 \mathrm{~g} / \mathrm{cm}^{2}$ (Melin et al., 2015)

- Intake assessment of food and beverage

While it would appear to be logical to measure EA as the main diagnostic indicator of RED-S, the accurate measurement of EA outside of a rigorously controlled laboratory setting is challenging given the lack of reliable, validated, and practical standardized protocols for identifying LEA, EI, EE, or FFM (Guebels et al., 2014). As such, clinicians must rely on secondary signs of LEA as indicators of RED-S, which are outlined in the RED-S screening box above.

\section{Eating Disorders/Disordered Eating}

To facilitate the diagnosis of ED/DE, Martinsen et al. (2014a) developed a validated screening tool designed to distinguish between female elite athletes with and without EDs/DE. The Brief Eating Disorder in Athletes Questionnaire (Martinsen et al., 2014b) can easily be implemented in electronic or paper format. In addition, the low energy availability in females questionnaire is a screening tool for the identification of female athletes at risk (Melin, Tornberg, et al., 2014).

\section{Body Composition}

Because of the pressure to be lean, both male and female artistic swimmers are at risk of developing DE and EDs (Benardot \& Thompson, 1999; de Sousa Fortes et al., 2013; Sundgot-Borgen \& Garthe, 2011). In addition to the pressure to be lean, there is also the need to match the physique of teammates (Robertson et al., 2014). Many artistic swimmers have eating anxiety, fearing that eating appropriate foods and beverages will negatively alter body composition and increase body mass (Haase et al., 2002; Krane et al., 2001; Vardar et al., 2007). "Weight" per se may be an inappropriate measure to determine if the desired body composition is being achieved, as weight is composed of proportionately more muscle and less fat, which is clearly better for both performance and appearance than a lower body mass with proportionately less muscle and more fat (Benardot, 2007). Body composition assessment of artistic swimmers should include informed consent, with the purpose clearly stated as monitoring any potential unhealthy changes and determining if training and dietary strategies are having the optimal result. Strategies for achieving safe and sensitive body composition screening can be found in the body composition section of Table 2 (Benardot, 2002).

\section{Treatment of RED-S}

\section{Nutritional Considerations}

The training program of elite artistic swimming can average $7 \mathrm{hr} /$ day for 6 days/week, including technical as well as additional training methods (weights, ballet, Pilates, acrobatics, flexibility, and conditioning). The schedule traditionally involves minimal and limited breaks, and as such, athletes have reported difficulty in consuming adequate energy and fluid. The nutritional plan should consider appropriate timing of meals and snacks, and coaches should allow sufficient breaks for proper fueling and hydration. A failure to adequately satisfy the increased nutrient requirement through food may (a) place the athlete at a higher injury risk, (b) fail to optimally reduce muscle soreness and enhance muscle recovery, (c) negatively impact the immune system to increase illness frequency, and (d) negatively alter both power and endurance (Pyne et al., 2014).

A unique training characteristic of artistic swimming involves spending a large percentage of the time upside down in the water as well as performing spinning maneuvers. Reflux may contribute to 


\section{Nutritional recommendations}

To optimize training performance, athletes should

- choose a well-balanced diet with nutrient-dense food choices sufficient in energy, carbohydrate, and protein

- consider appropriate timing of meals and snacks (before, during, and after training)

- consume sufficient calories, matching differential energy expenditures

- ensure proper recovery protocol (protein and $\mathrm{CHO}$ choice after training)

- discourage athlete weight loss close to major competitions

Energy

- aim to have athletes in adequate/optimal EA

- periodized to match the demands of training

- individually adjusted for each athlete

$\mathrm{CHO}$

- recommended range of 5-7 g CHO per kg body mass/day

- timing of $\mathrm{CHO}$ ingestion should occur at frequent intervals throughout the day (before, during, and after training)

Protein

- recommended range of $1.5-1.7 \mathrm{~g}$ protein/per kg body mass/day

- emphasis on timing

- include $20 \mathrm{~g}$ of high-quality protein 4 times per day (e.g., meat, fish, poultry, eggs, peanut butter, nuts)

Fat

- consume healthy fats as part of the overall diet (e.g., nuts, fatty fish, olive oil, avocado)

- recommended range of 20-25\% of total daily energy intake

Micronutrients

Ensure adequate intake of

- iron (red meat, beans, and iron-fortified cereals)

- calcium (dairy products, calcium-fortified juices, and fish with bones)

- vitamin D (fortified food products)

Use a combination of dietary sources (preferable) and supplements (if required)

To help prevent gastrointestinal upset

- choose easily digestible food choices

- avoid eating large volumes of food

- avoid eating high-fiber and gas-producing foods

- use an antacid (if required) to prevent gastrointestinal symptoms

Strategies to treat LEA

- an increase in energy intake and decrease in exercise is necessary

- an eating plan with an increase in current energy intake by $300-600 \mathrm{kcal} / \mathrm{day}$

- address suboptimal or mismanaged nutritional practices, timing of intake, and stress surrounding eating

\section{Annual PHE}

- Recognize that menstrual dysfunction is a sign of underlying pathology, and not regarded as a natural result of intense training

- Include blood and urine tests to assess iron, vitamin D status, and hydration state

- Include BMD (measured by DEXA) in athletes with LEA, DE/ED, or amenorrhea

- Include RED-S screening as part of the annual PHE

- Utilize the RED-S CAT intended for sports medicine professionals to assist with screening and management of athletes with RED-S

Body composition assessment

- Body composition assessment should occur at the beginning of the season, and in consultation with a sport dietitian, body composition manipulation should occur in a safe manner over a long period of time

- DEXA would be the preferred method for assessing body composition

- Athletes should be informed that the purpose is to monitor any potential unhealthy changes and to determine if training and dietary strategies are having the desired result

- Strategies for achieving this include

$\checkmark$ obtaining body composition values with only one athlete at a time

$\checkmark$ appropriate phrasing of results

$\checkmark$ providing athletes with information on how they have changed between assessments

$\checkmark$ increasing the focus on muscle mass and decreasing the focus on body fat

$\checkmark$ using body composition values to explain changes in performance

$\checkmark$ focusing on the changes in body composition to recommend dietary changes

$\checkmark$ avoiding any punitive action as a result of the assessed values

\section{Education strategies}

- Nutritional education strategies to help athletes and coaches understand the range of health and performance issues related to suboptimal eating practices to help reduce potential triggers

- Utilize the RED-S conceptual models to show the health and performance consequences

- Educate coaches to allow sufficient breaks in training to allow athletes to properly fuel and hydrate

- Implement prevention programs and the RED-S CAT tool within athlete-monitoring programs by FINA, as well as national sport governing bodies

Note. RED-S = relative energy deficiency in sport; $\mathrm{CHO}=$ carbohydrate; $\mathrm{EA}=$ energy availability; LEA = low energy availability; $\mathrm{PHE}=$ periodic health examination; DEXA = dual-energy X-ray absorptiometry; $\mathrm{DE}=$ disordered eating; $\mathrm{ED}=$ eating disorders; RED-S CAT = relative energy deficiency in sport clinical assessment tool;

FINA = Fédération Internationale de Natation; $\mathrm{BMD}=$ bone mineral density. 
LEA through voluntary restriction of food intake prior to training to avoid gastrointestinal symptoms while training. To help prevent gravitational esophageal reflux, athletes should choose easily digestible foods, avoid eating large volumes and high fiber/gas-producing foods, and use an antacid if required (Robertson et al., 2014).

Energy. Energy requirements for artistic swimmers vary depending on the phase of training, volume load, and tapering for competition. Energy intake should be periodized to match the demands and individually adjusted for each athlete (Loucks et al., 2011). In addition, the gender, age, and body composition of the athlete should be considered. As perceived fatigue is associated with LEA, adequate EI should be a priority during heavy training in artistic swimmers (Schaal et al., 2017). It is recommended that artistic swimmers consume sufficient calories matching differential EEs, with a focus on carbohydrate and protein (Cialdella-Kam et al., 2014). Preexercise and postexercise consumption of carbohydrate and protein influence muscle protein synthesis, muscle soreness, and recovery (Cermak et al., 2009; Gibala, 2002); therefore, the timing of energy and nutrient intake should be considered in the nutritional assessment, with the goal of consistent energy balance to assure optimal nutrient utilization and to optimize performance and recovery. A study by Fahrenholtz et al. (2018) found that within-day energy deficiency (as seen in those who train long periods of time without adequate/appropriate nutrition breaks, as is the training culture in artistic swimming), can result in markers of energy deficiency, such as changes in reproductive hormones. To treat LEA, an increase in EI and a decrease in exercise may be necessary. Strategies should include an eating plan with an increase in current EI by 300-600 kcal/day and should address suboptimal or mismanaged nutritional practices, timing of intake, and stress surrounding eating (Mountjoy et al., 2014).

Carbohydrates. Carbohydrates play a key role in helping maintain EA during training as well as optimizing the function of the immune system (Burke et al., 2006; Pyne et al., 2014). Athletes who restrict total calories to decrease body weight may have difficulty in achieving carbohydrate recommendations (Burke et al., 2001). Female athletes are often deficient in energy, especially energy in the form of carbohydrates, resulting in compromised health and performance (Loucks, 2004). The recommended reference range of carbohydrate intake for a sport with demands like artistic swimming is 5-7 g per kg body mass per day (Burke \& Kiens, 2004; Robertson et al., 2014). The timing of carbohydrate ingestion should occur at frequent intervals throughout the day, including before, during, and after training.

Protein. Elite artistic swimmers should aim for a protein intake range of $1.5-1.7 \mathrm{~g}$ of protein per $\mathrm{kg}$ body mass per day, with an emphasis on timing, to sustain or increase muscle mass (PaddonJones \& Rasmussen, 2009; Tipton et al., 2007). This range provides flexibility and should be individualized based on the athlete's requirements. Athletes should be encouraged to meet protein requirements by including $20 \mathrm{~g}$ of high quality, protein rich foods four times per day (Areta et al., 2013). Tipton and Phillips (2013) suggest that not all protein sources are equal in terms of their capacity to stimulate muscle protein synthesis, suggesting that dairy proteins (whey protein) are the superior choice. A study on Japanese rhythmic gymnasts found that a low protein intake was significantly associated with iron deficiency, highlighting the importance of protein intake (Kokubo et al., 2015).

Fat. Fat provides essential fatty acids, fat-soluble vitamins, and energy. Athletes should strive for fat intake to be $20-25 \%$ of total energy consumption (Rodriguez et al., 2009). Healthy fats (e.g., from nuts, olive oil, fatty fish, and avocado) are an important contributor to total energy intake. A diet too low in fat has the potential to compromise the immune system (Pyne et al., 2014). The challenge is that artistic swimmers often have an underlying fear of consuming fat-containing foods for ill-conceived body image reasons.

Nutrition for Recovery. Adequate EI is also a key in optimizing recovery. Schaal et al. (2017) demonstrated that artistic swimmers with prolonged LEA perceived the highest fatigue ratings, which may have decreased their ability to recover from high-intensity training. Consuming foods at regular recovery intervals can ensure adequate EI to prevent LEA. Integration of recovery eating needs to complement the athlete's overall nutritional goals, including energy requirements, body composition, and nutrient requirements (Burke \& Mujika, 2014). Artistic swimmers have individual recovery requirements based on the training phase, and the recovery protocol should be fine-tuned according to their needs. Since there can be a tendency for these athletes to restrict eating, attention should be given to ensuring adequate EI to achieve glycogen recovery.

\section{Medical Treatment of RED-S}

Due to the complexity of the various body systems and psychological involvement, successful treatment may require the utilization of a multidisciplinary team. Although it is not part of the treatment team, given the importance of the coach in the manipulation of body composition in the culture of artistic swimming, coach engagement in the treatment plan is essential to ensure compliance with a potential decrease in physical activity that may be required to reverse LEA (Mountjoy et al., 2014).

Psychological treatment depends on the type, severity, and duration of the problem. Comorbidities such as depression and anxiety may require pharmacotherapy in addition to various forms of psychotherapy. If there is a risk of self-harm, in-patient care may be required. If an athlete is not able to follow the treatment plan, it is usually indicative of an underlying psychological issue (Mitchell et al., 2013).

OCs do not address the underlying etiological factor, and thus the reversal of LEA should be the focus of treatment of MD. OCs also potentially have a negative effect on BMD, as well as masking amenorrhea, thus making it impossible to monitor EA as indicated by healthy menstrual function (Warren et al., 2005).

Underlying causes for low BMD should be identified and corrected. Research from low BMD in ED patients identifies that weight gain is effective in improving BMD (Misra \& Klibanski, 2011). Bone loading has also been shown to improve BMD. Current recommendations for daily calcium intake are 1,000 $\mathrm{mg}$ /day of calcium for men and women ages 19-50 years, and $1,300 \mathrm{mg} /$ day for adolescents and young adults ages 9-18 years (U.S. Department of Health and Human Services and U.S. Department of Agriculture, 2015). Vitamin D intake of 1,500 2,000 IU/day is also recommended (Holick et al., 2011). While transdermal estrogen and OC (estradiol) has been shown to improve BMD in anorexic patients, the use of OC treatment in FHA has been shown to decrease BMD. The bisphosphonates, which inhibit bone resorption, are not recommended in premenopausal women, but they can be prescribed safely in men (Papapoulos \& Cremers, 2007).

The IOC writing team developed a RED-S return-to-play model to assist the treatment team in the decision making of return to play. Reassessments of progress at specified time intervals 
(i.e., monthly) allow for reclassification of the athlete's risk, and subsequent changes to athlete sport participation are then realized in a graduated progression (Mountjoy et al., 2014). The use of an athlete contract is recommended to facilitate athlete compliance and to ensure that all members of the treatment team are informed.

\section{RED-S Prevention Strategies}

While early detection and effective treatment are important to prevent secondary health and performance consequences of RED-S, primary prevention strategies are essential to decrease the prevalence of RED-S in artistic swimming. Table 2 outlines RED-S prevention strategies for this athlete population. A survey of International Sport Federations' medical programs revealed that only $7 \%$ of summer Olympic sports had programs on RED-S, indicating a general lack of knowledge and support for elite athletes with RED-S (Mountjoy et al., 2018). Therefore, educational initiatives should target sport organizations in addition to athletes and coaches.

\section{Conclusion}

Given the risk of RED-S in artistic swimming, FINA should focus on educating athletes, coaches, and medical professionals on the health and performance consequences of RED-S to stimulate prevention through raising awareness and to improve early detection and treatment. Future research in artistic swimming is needed to (a) determine the prevalence of RED-S in this population of both male and female athletes, (b) validate assessment tools to identify LEA, and (c) critically analyze the efficacy of treatment interventions.

\section{Acknowledgment}

The authors have no conflict of interest to declare.

\section{References}

Ackerman, K.E., Nazem, T., Chapko, D., Russell, M., Mendes, N., Taylor, A.P., ... Misra, M. (2011). Bone microarchitecture is impaired in adolescent amenorrheic athletes compared with eumenorrheic athletes and nonathletic controls. Journal Clinical Endocrinology \& Metabolism, 96(10), 3123-3133. doi:10.1210/jc.2011-1614

Ackerman, K.E., Putman, M., Guereca, G., Taylor, A.P., Pierce, L., Herzog, D.B., ... Misra, M. (2012). Cortical microstructure and estimated bone strength in young amenorrheic athletes, eumenorrheic athletes and non-athletes. Bone, 51(4), 680-687. PubMed ID: 22878154 doi:10.1016/j.bone.2012.07.019

Areta, J.L., Burke, L.M., Ross, M.L., Camera, D.M., West, D.W., Broad, E.M., ... Coffey, V.G. (2013). Timing and distribution of protein ingestion during prolonged recovery from resistance exercise alters myofibrillar protein synthesis. Journal of Physiology, 591(9), 2319-2331. PubMed ID: 23459753 doi:10.1113/jphysiol.2012. 244897

Bante, S., Bogdanis, G.C., Chairopoulou, C., \& Maridaki, M. (2007). Cardiorespiratory and metabolic responses to a simulated synchronized swimming routine in senior and comen national level athletes. Journal of Sports Medicine \& Physical Fitness, 47, 291-299. PubMed ID: 17641595

Barrack, M.T., Fredericson, M., Tenforde, A.S., \& Nattiv, A. (2017). Evidence of a cumulative effect for risk factors predicting lower bone mass among male adolescent athletes. British Journal of Sports Medicine, 51(3), 200-205. PubMed ID: 29461218 doi:10.1136/ bjsports-2016-096698

Baxter-Jones, A.D., Faulkner, R.A., Forwood, M.R., Mirwald, R.L., \& Bailey, D.A. (2011). Bone mineral accural from 8-30 years of age: An estimate of peak bone mass. Journal of Bone and Mineral Research, 26, 1729-1739. PubMed ID: 21520276

Benardot, D. (2002). NCAA: Guideline 2e-assessment of body composition. In D. Klossner (Ed.), NCAA sports medicine handbook (14th ed.; pp. 34-38). Indianapolis, IN: National Collegiate Athletic Association.

Benardot, D. (2007). Timing of energy and fluid intake: New concepts for weight control and hydration. ACSM's Health \& Fitness Journal, 11(4), 13-19. PubMed ID: 29692203

Benardot, D., \& Thompson, W.R. (1999). Energy from food for physical activity: Enough and on time. ACSM's Health \& Fitness Journal, 3(4), 14-18. PubMed ID: 29692203

Berkovich, B.E., Eliakim, A., Nemet, D., Stark, A.H., \& Sinai, T. (2016). Rapid weight loss among adolescents participating in competitive judo. International Journal Sport Nutrition and Exercise Metabolism, 26(3), 276-284. doi:10.1123/ijsnem.2015-0196

Burke, L.M., Cox, G., Cummings, N., \& Desbrow, B. (2001). Guidelines for daily carbohydrate intake: Do athletes achive them? Sports Medicine, 31, 267-299. PubMed ID: 11310548 doi:10.2165/ 00007256-200131040-00003

Burke, L.M., Kiens, B., \& Ivy, I. (2004). Carbohydrate and fat for training and recovery. Journal of Sports Sciences, 22, 15-30. doi:10.1080/ 0264041031000140527

Burke, L.M., Loucks, A., \& Broad, N. (2006). Energy and carbohydrate for training and recovery. Journal of Sport Sciences, 24, 675-685. doi: $10.1080 / 02640410500482602$

Burke, L.M., \& Mujika, I. (2014). Nutrition for recovery in aquatic sports. International Journal of Sport Nutrition and Exercise Metabolism, 24, 425-436. PubMed ID: 24901517 doi:10.1123/ijsnem.2014-0022

Cermak, N.M., Solheim, A.S., Gardner, M.S., Tarnopolsky, M.A., \& Gibala, M.J. (2009). Muscle metabolism during exercise with carbohydrate ingestion. Medicine \& Science in Sports \& Exercise, 41, 2158-2164. PubMed ID: 19915503 doi:10.1249/MSS 0b013e3181ac10bf

Chatard, J.C., Mujika, I., Chantegraille, M.C., \& Kostucha, J. (1999). Performance and physiological responses to a 5-week synchronized swimming technical training programme in humans. European Journal of Applied Physiology, 79, 479-483. doi:10.1007/ s004210050540

Cialdella-Kam, L., Guebels, C.P., Maddalozzo, G.F., \& Manore, M.M. (2014). Dietary intervention restored menses in female athletes with exercise-associated menstrual dysfunction with limited impact on bone and muscle health. Nutrients, 6(8), 3018-3039. PubMed ID: 25090245 doi:10.3390/nu6083018

Constantini, N.W. (2002). Medical concerns of the dancer. Book of Abstracts, XXVII FIMS World Congress of Sports Medicine, Budapest, Hungary, 151.

de Sousa Fortes, L., Neves, C.M., Filgueiras, J.F., Almeida, S.S., \& Ferreira, M.E.C. (2013). Body dissatisfaction, psychological commitment to exercise and eating behavior in young athletes from aesthetic sports. Brazilian Journal of Kinanthropometry and Human Performance, 15, 695-704.

De Souza, M.J., Nattiv, A., Joy, E., Misra, M., Williams, N.I., Mallinson, R.J., ... Expert Panel. (2014). Female athlete triad coalition consensus statement on treatment and return to play of the female athlete triad: 1st International conference held in San Francisco, California, May 2012 and 2nd International Conference held in 
Indianapolis, Indiana, May 2013. British Journal of Sports Medicine, 48(4), 289. PubMed ID: 24463911 doi:10.1136/bjsports-2013093218

De Souza, M.J., Toombs, R., Scheid, J., O’Donnell, E., West, S., \& Williams, N. (2010). High prevalence of subtle and severe menstrual disturbances in exercising women: Confirmation using daily hormone measures. Human Reproduction, 25, 491-503. PubMed ID: 19945961 doi:10.1093/humrep/dep411

Douka, A., Skordilis, E., Koutsouki, D., \& Theodorakis, Y. (2008). Prevalence of eating disorders among elite female athletes in aquatic sports. Inquiries in Sport \& Physical Education, 6, 87-96.

Ebine, N., Feng, J.Y., Homma, M., Saitoh, S., \& Jones, P.J.H. (2000). Total energy expenditure of elite synchronized swimmers measured by the doubly labelled water method. European Journal of Applied Physiology, 83, 1-6. PubMed ID: 11072766 doi:10.1007/ s004210000253

Fahrenholtz, I.L., Sjodin, A., Benardot, D., Tornberg, A.B., Skouby, S., Faber, J., ... Melin, A.K. (2018). Within-day energy deficiency and reproductive function in female endurance athletes. Scandinavian Journal of Medicine \& Science in Sports, 28(3), 1139-1146. PubMed ID: 29205517 doi: $10.1111 / \mathrm{sms} .13030$

Ferrand, C., Magnan, C., Rouveix, M., \& Filare, E. (2007). Disordered eating, perfectionism and body-esteem of elite synchronzied swimmers. European Journal of Sport Science, 7, 223-230. doi:10.1080/ 17461390701722168

Gibala, M.J. (2002). Dietary protein, amino acid supplements, and recovery from exercise. GSSI Sports Science Exchange, 15, 1-4.

Gibbs, J.C., Nattiv, A., Barrack, M.T., Williams, N.I., Rauh, M.J., Nichols, J.F., \& De Souza, M.J. (2014). Low bone density risk is higher in exercising women with multiple triad risk factors. Medicine \& Science in Sports \& Exercise, 46, 167-176. PubMed ID: 23783260 doi:10.1249/MSS.0b013e3182a03b8b

Guebels, C.P., Kam, L.C., Maddalozzo, G.F., \& Manore, M.M. (2014). Active women before/after an intervention designed to restore menstrual function: Resting metabolic rate and comparison of four methods to quantify energy expenditure and energy availability. International Journal of Sport Nutrition \& Exercise Metabolism, 24(1), 37-46. doi:10.1123/ijsnem.2012-0165

Haase, A.M., Prapavessis, H., \& Owens, R.G. (2002). Perfectionism, social physique anxiety and disordered eating: A comparison of male and female elite athletes. Psychology of Sport and Exercise, 3, 209-222. doi:10.1016/S1469-0292(01)00018-8

Hagmar, M., Hirschberg, A.L., Berglund, L., \& Berglund, B. (2008). Special attention to the weight-control strategies employed by Olympic athletes striving for leanness is required. Clinical Journal of Sport Medicine, 18, 5-9. PubMed ID: 18185032 doi:10.1097/JSM. 0b013e31804c77bd

Holick, M.F., Binkley, N.C., Bischoff-Ferrari, H.A., Gordon, C.M., Hanley, D.A., Heaney, R.P., ... Weaver, C.M. (2011). Evaluation, treatment, and prevention of vitamin D deficiency, an endocrine society clinical practice guideline. Journal of Clinical Endocrinal Metabolism, 96, 1911-1930. doi:10.1210/jc.2011-0385

Homma, M. (1994). The components and the time of "face in" of the routines in synchronized swimming. In M. Miyashi, Y. Mutoh, \& A.B. Richardson (Eds.), Medicine and science in aquatic sports (pp. 149-154). Basel, Switzerland: Karger.

Khan, K., Liu-Ambrose, T., Sran, M., Ashe, M., Donaldson, M., \& Wark, J. (2002). New criteria for female athlete triad syndrome? As osteoporosis is rare, should osteopenia be among the criteria for defining the female athlete triad syndrome? British Journal of Sports Medicine, 36, 10-13. PubMed ID: 11867483 doi:10.1136/bjsm. 36.1.10
Kokubo, Y., Yokoyama, Y., Kisara, K., Ohira, Y., Sunami, A., Yoshizaki, T., ... Kawano, Y. (2015). The relationship between dietary factors and bodily iron status among Japanese collegiate female rhythmic gymnasts. International Journal of Sport Nutrition and Exercise Metabolism, 26(2), 105-113. PubMed ID: 26322906 doi:10.1123/ ijsnem.2015-0123

Krane, V., Waldron, J., Stiles-Shipley, J.A., \& Michalenok, J. (2001). Relationships among body satisfaction, social physique anxiety, and eating behaviors in female athletes and exercisers. Journal of Sport Behavior, 24, 247-265.

Liang, M., Arnaud, S., Steele, C., Hatch, P., \& Moreno, A. (2005). Ulnar and tibial bending stiffness as an index of bone strength in synchronized swimming and gymnasts. European Journal of Applied Physiology, 94, 400-407. PubMed ID: 15864633 doi:10.1007/ s00421-005-1351-2

Ljungqvist, A., Jenoure, P.J., Engebretsen, L., Alonso, J.M., Bahr, R., Clough, A.F., ... Dubi, C. (2009). The International Olympic Committee (IOC) Consensus Statement on periodic health evaluation of elite athletes. Clinical Journal of Sport Medicine, 19, 347-365. PubMed ID: 19741306 doi:10.1097/JSM.0b013e3181b7332c

Loucks, A.B. (2004). Energy balance and body composition in sports and exercise. Journal of Sports Sciences, 22, 1-14. PubMed ID: 14974441 doi:10.1080/0264041031000140518

Loucks, A.B., Kiens, B., Wright, H.H. (2011). Energy availability in athletes. Journal of Sports Sciences, 29(S1), S7-S15. doi:10.1080/ 02640414.2011.588958

Martinsen, M., Bahr, R., Borresen, R., Holme, I., Pensgaard, A.M., \& Sundgot-Borge, J. (2014a). Preventing eating disorders among young elite athletes: A randomized controlled trial. Medicine \& Science in Sports \& Exercise, 46, 435-447. doi:10.1249/MSS.0b013e3182 a702fc

Martinsen, M., Holme, I., Pensgaard, A.M., Klungland Torstveit, M., \& Sundgot-Borgen, J. (2014b). The development of the Brief Eating Disorder in Athletes questionnaire (BEDA-Q). Medicine \& Science in Sports \& Exercise, 46(8), 1666-1675. doi:10.1249/MSS.0000 000000000276

Martinsen, M., \& Sundgot-Borgen, J. (2013). Higher prevalence of eating disorders among adolescent elite athletes than controls. Medicine Science in Sports \& Exercise, 45(6), 1188-1197. doi:10.1249/MSS. 0b013e318281a939

Melin, A., Klungland Torstveit, M., Burke, L., Marks, S., \& SundgotBorgen, J. (2014). Disordered eating and eating disorders in aquatic sports. International Journal of Sport Nutrition and Exercise Metabolism, 24, 450-459. PubMed ID: 24667155 doi:10.1123/ijsnem. 2014-0029

Melin, A., Tornberg, A.B., Skouby, S., Faber, J., Ritz, C., Sjödin, A., \& Sundgot-Borgen, J. (2014). The LEAF questionnaire: A screening tool for the identification of female athletes at risk for the female athlete triad. British Journal of Sports Medicine, 48, 540-545. PubMed ID: 24563388 doi:10.1136/bjsports-2013-093240

Melin, A., Tornberg, A.B., Skouby, S., Moller, S.S., Sundgot-Borgen, J., Faber, J., ... Sjodin, A. (2015). Energy availability and the female athlete triad in elite endurance athletes. Scandinavian Journal of Medicine \& Science in Sports, 25(5), 610-622. PubMed ID: 24888644 doi:10.1111/sms.12261

Misra, M., \& Klibanski, A. (2011). Bone health in anorexia nervosa. Current Opinion in Endocrinology, Diabetes, and Obesity, 18(6), 376-382. PubMed ID: 21897220 doi:10.1097/MED.0b013e $32834 b 4 b d c$

Mitchell, J.E., Roerig, J., \& Steffen, K. (2013). Biological therapies for eating disorders. International Journal of Eating Disorders, 46(5), 470-477. PubMed ID: 23658094 doi:10.1002/eat.22104 
Mountjoy, M. (2009). Injuries and medical issues in the synchronized Olympic sports. Current Sports Medicine Reports, 8, 255-261. PubMed ID: 19741353 doi:10.1249/JSR.0b013e3181b84a09

Mountjoy, M., Costa, A., Budgett, R., Dvorak, J., Engebretsen, L., Miller, S., . . C Carr, J. (2018). Health promotion through sport: International Sport Federations' priorities, actions and opportunities. British Journal of Sports Medicine, 52(1), 54-60. PubMed ID: 28701361 doi: 10.1136/bjsports-2017-097900

Mountjoy, M., Sundgot-Borgen, J., Burke, L., Carter, S., Constantini, N., Lebrun, C., ... Ackerman, K. (2015). The IOC relative energy deficiency in sport clinical assessment tool (RED-S CAT). British Journal of Sports Medicine, 49(7), 421-424. PubMed ID: 25896450 doi:10.1136/bjsports-2014-094371

Mountjoy, M., Sundgot-Borgen, J., Burke, L., Carter, S., Constantini, N., Lebrun, C., .. L Lungqvist, A. (2014). The IOC Consensus Statement. Beyond the female athlete triad-Relative energy deficiency in sport. British Journal of Sports Medicine, 48, 491-497. PubMed ID: 24620037 doi:10.1136/bjsports-2014-093502

Nattiv, A., Loucks, A.B., Manore, M.M., Sanborn, C.F., SundgotBorgen, J., \& Warren, M.P. (2007). American College of Sports Medicine position stand. The female athlete triad. Medicine \& Science in Sports \& Exercise, 39, 1867-1882. PubMed ID: 17909417

Paddon-Jones, D., \& Rasmussen, B.B. (2009). Dietary protein recommendations and the prevention of sarcopenia: Protein amino acid metabolism and therapy. Current Opinion in Clinical Nutrition and Metabolic Care, 12(1), 86-90. PubMed ID: 19057193 doi:10.1097/ MCO.0b013e32831cef8b

Papapoulos, S.E., \& Cremers, S.C. (2007). Prolonged bisphosphonate release after treatment in children. The New England Journal of Medicine, 356(10), 1075-1076. PubMed ID: 17347467 doi:10.1056/ NEJMc062792

Petkus, D.L., Murray-Kolb, L.E., \& De Souza, M.J. (2017). The unexplored crossroads of the female athlete triad and iron deficiency: A narrative review. Sports Medicine, 47(9), 1721-1737. PubMed ID: 28290159 doi:10.1007/s40279-017-0706-2

Pyne, D.B., Verhagen, E.A., \& Mountjoy, M. (2014). Nutrition, illness, and injury in aquatic sports. International Journal of Sport Nutrition and Exercise Metabolism, 24, 460-469. PubMed ID: 24937101 doi:10.1123/ijsnem.2014-0008

Ramsay, R., \& Wolman, R. (2001). Are synchronized swimmers at risk of amenorrhea? British Journal of Sports Medicine, 35, 242-244. PubMed ID: 11477017 doi:10.1136/bjsm.35.4.242

Rauh, M., Nichols, J., \& Barrack, M. (2010). Relationships among injury and disordered eating, menstrual dysfunction, and low bone mineral density in high school athletes: A prospective study. Journal of Athletic Training, 45, 243-252. PubMed ID: 20446837 doi:10. 4085/1062-6050-45.3.243

Robertson, S., Benardot, D., \& Mountjoy, M. (2014). Nutritional recommendations for synchronized swimming. International Journal of Sport Nutrition and Exercise Metabolism, 24, 404-413. PubMed ID: 24667278 doi:10.1123/ijsnem.2014-0013

Roby, F., Atwater, A., Going, S., Lohman, T., Puhl, J., \& Tucker, M. (1988). Bone mineral content in synchronized swimmers. In: Proceedings of the First IOC World Congress on Sports Sciences, October 28 1989-November 3 1989. Colorado Springs, CO: US Olympic Committee.

Rodriguez, N.R., DiMarco, N.M., Langley, S., American Dietetic Association, Dietitians of Canada, \& American College of Sports Medicine. (2009). Position of the American Dietetic Association, Dietitians of Canada and the American College of Sports Medicine. Nutrition and athletic performance. Journal of the American Dietetic Association,
109, 509-527. PubMed ID: 19278045 doi:10.1016/j.jada.2009. 06.104

Rosendahl, J., Bormann, B., Aschenbrenner, K., Aschenbrenner, F., \& Strauss, B. (2009). Dieting and disordered eating in German high school athletes and non-athletes. Scandinavian Journal of Medicine \& Science in Sports, 19(5), 731-739. PubMed ID: 18627556 doi: 10.1111/j.1600-0838.2008.00821.x

Sambanis, M., Kofotolis, N., Kalogeropoulou, E., Noussios, G., Sambanis, P., \& Kalogeropoulos, J. (2003). A study on the effects on the ovarian cycle of athletic training in different sports. Journal of Sports Medicine \& Physical Fitness, 43, 398-403. PubMed ID: 14625523

Schaal, K., Tiollier, E., Le Meur, Y., Casazza, G., \& Hausswirth, C. (2017). Elite synchronized swimmers display decreased energy availability during intensified training. Scandinavian Journal of Medicine \& Science in Sports, 27(9), 925-934. PubMed ID: 27367601 doi:10.1111/sms.12716

Sonntag, B., \& Ludwig, M. (2012). An integrated view on the luteal phase: Diagnosis and 60 treatment in subfertility. Clinical Endocrinology (Oxf), 77(4), 500-507. doi:10.1111/j.1365-2265.2012.04464.x

Sundgot-Borgen, J., \& Garthe, I. (2011). Elite athletes in aesthetic and Olympic weight-class sports and the challenge of body weight and body compositions. Journal of Sports Sciences, 29(Suppl. 1), S101-S114. doi:10.1080/02640414.2011.565783

Tanaka, C., Lida, T., Tawara, Y., Murata, M., Takamatsu, J., Honma, M., \& Kawahara, T. (2006). Characteristics of bone density in adolescent synchronized swimmers- Relationships between bone density, daily physical activity and dietary intake. Japanese Journal of Physical Fitness and Sports Medicine, 55, 165-174. doi:10.7600/jspfsm.55.165

Thein-Nissenbaum, J.M., Rauh, M.J., Carr, K.E., Lourd, K.J., \& McGuine, T.A. (2011). Associations between disordered eating, menstrual dysfunction, and musculoskeletal injury among high school athletes. Journal of Orthopaedic \& Sports Physical Therapy, 41, 60-69. PubMed ID: 21212503 doi:10.2519/jospt.2011.3312

Tipton, K.D., Elliott, T.A., Cree, M.G., Aarsland, A.A., Sanford, A.P., \& Wolfe, R.R. (2007). Stimulation of net muscle protein synthesis by whey protein ingestion before and after exercise. American Journal of Physiology-Endocrinology and Metabolism, 292, E71-E76. PubMed ID: 16896166 doi:10.1152/ajpendo.00166.2006

Tipton, K.D., \& Phillips, S.M. (2013). Dietary protein for muscle hypertrophy. Nestle Nutrition Institute Workshop Service, 76, 73-84.

U.S. Department of Health and Human Services and U.S. Department of Agriculture. (2015). 2015-2020 Dietary guidelines for Americans. (8th Ed.). December 2015. Available at http://health.gov/ dietaryguidelines/2015/guidelines/.

Vanheest, J.L., Rodgers, C.D., Mahoney, C.E., \& De Souza, M.J. (2014). Ovarian suppression impairs sport performance in junior elite female swimmers. Medicine \& Science in Sports \& Exercise, 46, 156-166. PubMed ID: 23846160 doi:10.1249/MSS.0b013e3182a32b72

Vardar, E., Vardar, S.A., \& Kurt, C. (2007). Anxiety of young female athletes with disordered eating behaviors. Eating Behaviors, 8(2), 143-147. PubMed ID: 17336783 doi:10.1016/j.eatbeh.2006. 03.002

Venkatraman, J.T., \& Pendergast, D.R. (2002). Effect of dietary intake on immune function in athletes. Sports Medicine, 32(5), 323-337. PubMed ID: 11929359 doi:10.2165/00007256-200232050-00004

Viner, R.T., Harris, M., Berning, J.R., \& Meyer, N.L. (2015). Energy availability and dietary patterns of adult male and female competitive cyclists with lower than expected bone mineral density. International Journal of Sport Nutrition and Exercise Metabolism, 25(6), 594-602. PubMed ID: 26131616 doi:10.1123/ijsnem.2015-0073

Warren, M.P., Miller, K.K., Olson, W.H., Grinspoon, S.K., \& Friedman, A.J. (2005). Effects of an oral contraceptive (norgestimate/ethinyl 
estradiol) on bone mineral density in women with hypothalamic amenorrhea and osteopenia: An open-label extension of a double-blind, placebo-controlled study. Contraception, 72(3), 206211. PubMed ID: 16102557 doi:10.1016/j.contraception.2005. 03.007
Wilson, G., Hawken, M.B., Poole, I., Sparks, A., Bennett, S., Drust, B., .. Close, G.L. (2014). Rapid weight-loss impairs simulated riding performance and strength in jockeys: Implications for makingweight. Journal of Sports Sciences, 32(4), 383-391. PubMed ID: 24015787 doi:10.1080/02640414.2013.825732 